\title{
Licitações Públicas: \\ um estudo o uso da dispensa e inexigibilidade de licitações no município de Bela Vista de Goiás, Brasil.
}

\author{
Public Bidding: \\ a study the use of dispensation and inexigibility of bids in the \\ municipality of Bela Vista de Goiás, Brazil.

\section{Licitaciones Públicas:} \\ um estudo o uso da dispensa e inexigibilidade de licitações \\ no município de Bela Vista de Goiás, Brasil.
}

Appel d'Offres Public:

une étude de l'utilisation de la renonciation et de l'inexigibilité des offres dans la municipalité de Bela Vista de

Goiás, Brésil. 
Resumo

\section{Abstract}

Este artigo tem por objetivo analisar se a Administração Pública do município de Bela Vista de Goiás utilizou de forma correta a dispensa e inexigibilidade de licitação nos anos de 2019 e 2020, atendendo os requisitos legais dos dispositivos que autorizam a contratação direta. Trata-se de uma pesquisa de natureza aplicada, de abordagem quali-quantitativa, classificada quanto aos objetivos como uma pesquisa exploratória. Em relação aos procedimentos técnicos adotou-se o estudo de caso. Para o levantamento das informações utilizou-se a extração de informações no portal da transparência, bem como acesso a pareceres disponibilizados pela prefeitura, através de requerimentos. Os resultados da pesquisa demonstraram que a secretaria que mais utilizou da dispensa de licitação foi a Secretaria de Saúde, concentrando a maior parte das dispensas para aquisição de insumos para o enfrentamento do COVID-19, seguindo o art. 24, mais especificamente os incisos I e II da Lei Federal ${ }^{\circ}$ 8.666/1993. Não foi possível identificar nenhum processo em que o munícipio tenha utilizado da inexigibilidade de licitação no período estudado. A pesquisa forneceu resposta à problemática proposta, vez que se verificou que a Administração Pública do município utilizou a dispensa de licitação atendendo a legislação em vigor, porém com algumas ressalvas.

Palavras-Chave: Administração Pública; Dispensa Licitatória; Inexigibilidade de Licitação; Compras Públicas; Políticas Públicas.

This article aims to analyze whether the Public Administration of the municipality of Bela Vista de Goiás correctly used the dispensation and unenforceability of bidding in the years 2019 and 2020, meeting the legal requirements of the devices that authorize direct contracting. It is a research of an applied nature, with a qualitative and quantitative approach, classified according to the objectives as an exploratory research. Regarding technical procedures, the case study was adopted. To collect the information, information extraction was used in the transparency portal, as well as access to opinions provided by the city hall, through requirements. The results of the research showed that the secretariat that used the bidding dispensation the most was the Secretariat of Health, concentrating most of the dispensations for the acquisition of inputs to face COVID-19, according to art. 24, more specifically, items I and II of Federal Law 8.666 / 1993. It was not possible to identify any process in which the municipality used the unenforceable bidding in the period studied. The survey provided an answer to the proposed problem, since it was found that the municipality's Public Administration used the waiver of bidding in compliance with the legislation in force, however with some reservations, as will be explained.

Keywords: Public Administration; Dispensation of Bidding; Inexigibility of Bidding; Public Procurement; Public Policies. 
Resumen

\section{Resumé}




\section{Introdução}

A licitação é um procedimento administrativo no qual a Administração Pública contrata empresas privadas para fornecimento de bens e serviços, podendo em alguns casos excepcionais dispensar o uso da licitação.

As normas para licitações e contratos da Administração Pública são regulamentadas pela Lei Federal $\mathrm{n}^{\circ} .8 .666 / 93$ e a dispensa de licitação poderão ocorrer apenas em casos especiais previstos no artigo 24 desta lei.

De acordo com o artigo $3^{\circ}$ da referida lei as licitações devem ser "processadas e julgadas em estrita conformidade com os princípios básicos da legalidade, da impessoalidade, da moralidade, da igualdade, da publicidade, da probidade administrativa". A falta dessas observâncias poderá ocasionar crime, podendo "gerar multa e detenção, de 3 (três) a 5 (cinco) anos". (BRASIL, 1993)

Sendo assim, o objetivo deste artigo é analisar se a Administração Pública do município de Bela Vista de Goiás utilizou de forma correta a dispensa e inexigibilidade de licitação nos anos de 2019 e 2020, atendendo os requisitos legais dos dispositivos que autorizam a contratação direta.

Hoje a cidade de Bela Vista de Goiás conta com um número populacional acima dos 28 mil e ainda está em processo de expansão, devido a sua localização favorável, a cidade possui um grande distrito industrial, no qual sua principal atividade econômica é a agropecuária oriunda da produção de leite e seus derivados, esses fatores fomentam a indústria local e aumenta a riqueza da cidade, consequentemente, isso faz com que a máquina pública municipal ganhe maior poder para comprar e adquirir bens e serviços, devendo assim, aumentar o controle e fiscalização sobre esses processos de compras.

A escolha do tema se deu por se tratar de um assunto de extrema importância para a Administração Pública no que se refere aos processos de aquisição e compra de bens e serviços, uma vez que possui fragilidades e lacunas na atual lei de licitação, que favorece a ocorrência de fraudes nas licitações e contratos, sendo, portanto, uma temática de grande importância no contexto atual. Diante de uma iminente crise financeira, devemos combater a corrupção e possíveis prejuízos à Administração Pública. A partir deste pensamento, adotamos como questão desta pesquisa: a dispensa de licitações realizadas pelo município de Bela Veja de Goiás nos anos de 2019 e 2020, foi tão rigorosa quanto às licitações?

Ante ao exposto, são objetivos específicos dessa pesquisa: expor com clareza como ocorreu o processo de dispensa de licitação pelo referido município nos anos de 2019 e 2020, bem como as justificativas apresentadas para a aplicação da dispensa e a inexigibilidade de licitação, analisar detalhadamente o momento ideal para a aplicação da dispensa e a inexigibilidade de licitação e se a Administração Pública do município atendeu os requisitos legais dos dispositivos que autorizam a contratação direta, e por fim, analisar as fragilidades e lacunas na atual lei de licitação, que favorece a ocorrência de fraudes nas licitações e contratos e que levam a danos e prejuízos nos casos de dispensa e inexigibilidade de licitação de forma inadequada.

Com a realização e a conclusão desta pesquisa pretende-se gerar mais conhecimento no campo acadêmico e trazer possíveis contribuições para o campo aplicado, em especial na gestão pública de Bela Vista de Goiás, pois é fundamental que o gestor tenha uma visão mais ampla das irregularidades na dispensa e inexigibilidade de licitação, que poderá ser combatida através da qualificação dos agentes públicos, evitando assim que haja irregularidades e corrupção, na Administração Pública. Para o campo social, pretende-se levar conhecimento e informações à população acerca da Lei Federal nº. 
8.666/93, que estabelece os critérios para que o dinheiro público seja utilizado de forma correta nos processos de dispensa e inexigibilidade de licitação.

\section{Revisão de Literatura}

A Constituição Federal de 1988 trouxe, pela primeira vez na história constitucional brasileira, a menção expressa do dever de licitar, incluído no inciso XXI do art. 37, que trata dos princípios e normas gerais da Administração Pública, bem como, no inciso XXVII do art. 22, no qual compete a União legislar sobre normas gerais de licitação e contração.

Seguindo esse contexto constitucional, precedeu a elaboração da Lei Federal no 8.666 em 1993, que estabelece normas gerais sobre licitações e contratos administrativos, bem como os casos de dispensa e de inexigibilidade de licitação, assim, podemos dizer que licitar é uma obrigação constitucional, porém, há possibilidade de arrolar os casos em que essa obrigação poderá ser excepcionada, "instituindo diferentes hipóteses de dispensa e/ou inexigibilidade de licitação, conforme entender necessário, tendo sempre em vista, no entanto, o imperativo de manter a regra geral da necessidade de licitar os contratos públicos". (Brasil, 1993)

Segundo Di Pietro (2003: 299):

A licitação é procedimento administrativo pelo qual um ente público, no exercício da função administrativa, abre a todos os interessados, que se sujeitem às condições fixadas no instrumento convocatório, a possibilidade de formularem propostas dentre as quais selecionará e aceitará a mais conveniente para celebração de contrato.

Segundo informações técnicas do Portal de Transparência do governo federal, a dispensa de licitação representa $38 \%$ das compras, aquisições e contratações contratado pelo governo, um valor alto, visto que, a dispensa deveria ser uma exceção. Para Bittencourt (1998:60) "licitação dispensável é aquela em que existe uma desobrigação de instauração de procedimento licitatório, caso seja conveniente ao interesse público. Licitação Inexigível é aquela que existe inviabilidade de competição, diante do total de impossibilidade de confronto".

Segundo os órgãos fiscalizadores (Ministério Público, Tribunal de Contas da União, Tribunal de Contas do Estado, Tribunal de Contas dos Municípios) o número de fraudes aumentou de forma significativa, por conta do atual cenário de pandemia e devido a publicação da Medida Provisória $\mathrm{n}^{\circ}$ 926, que alterou a Lei $n^{\circ} 13.979$, de 13 de fevereiro de 2020. O art. $4^{\circ}$ da lei com redação dada pela MP prevê a contratação por dispensa de licitação para "aquisição de bens, serviços, inclusive de engenharia, e insumos destinados ao enfrentamento da emergência de saúde pública, enquanto perdurar a emergência de saúde pública" (BRASIL, 2020). Fato este que fez com que criasse uma CPI para investigar todos contratos fechados durante a pandemia, com grandes indícios de fraudes nas dispensas de licitação, objeto dessa pesquisa.

De acordo com Anderson de Oliveira (2009, pag. 29) e dados obtidos junto ao Tribunal de Contas da União, dentre as fraudes mais comuns, estão: "o superfaturamento e a dispensa de licitação, um 
caminha com o outro, pois a dispensa é utilizada para fechar contratos com preços superiores aos praticados no mercado". Os valores aceitos pela Comissão de Licitação superam o valor da pesquisa de mercado, que muitas vezes, é consequência de acordo prévio entre os concorrentes. Diante disto, é que se torna fundamental averiguar se a Administração Pública do município de Bela Vista de Goiás está utilizando de forma correta a dispensa e inexigibilidade de licitação atendendo os requisitos legais dos dispositivos que autorizam a contratação direta.

Os autores aqui citados destacam a grande importância da gestão ágil, correta e justa, pois os estudos realizados buscam diminuir a incidência dos crimes contra a Administração Pública e um maior rigor ao cumprimento efetivo do que está na lei, combatendo a corrupção e trazendo contribuições para a gestão pública.

\section{Metodologia}

Esta é uma pesquisa de natureza aplicada, de abordagem quali-quantitativa, classificada quanto aos objetivos como uma pesquisa exploratória. Em relação aos procedimentos técnicos adotou-se o estudo de caso. Para o levantamento das informações utilizou-se a extração de informações no portal da transparência do município de Bela Vista de Goiás, bem como do acesso a pareceres e ofícios autorizando e justificando a dispensa e inexigibilidade de licitações referente aos anos de 2019 e 2020, disponibilizados pela Prefeitura, através de requerimento por e-mail e por telefone.

As informações obtidas a partir do acesso aos documentos foram categorizadas, e posteriormente feita uma análise de conteúdo chegando assim às considerações finais e a possíveis contribuições.

\section{Resultados e Discussão}

Os resultados aqui apresentados foram com base no relatório de procedimentos licitatórios extraídos do Portal de Transparência e também de cópia dos pareceres e ofícios autorizando e justificando a dispensa e inexigibilidade de licitações disponibilizados pela Secretaria de Controle Interno da Prefeitura de Bela Vista de Goiás. Conforme previsto na própria Constituição Federal, no qual prevê no seu artigo $5^{\circ}$, inc. XXXIII "todos têm direito a receber dos órgãos públicos informações de seu interesse particular, ou de interesse coletivo ou geral" (BRASIL, 1988). promovendo o exercício do controle social, resta esclarecer que, esta Secretaria é o departamento responsável por emitir parecer com os fundamentos nos procedimentos relativos à contratação dispensável de licitação, 
declarando se o referido processo se encontra revestido de todas as formalidades legais, estando apto ou não a gerar despesas para a municipalidade. Ressalta-se que na análise foram considerados os documentos disponibilizados pelo departamento, bem como as informações dos autores envolvidos neste processo, sob o aspecto da veracidade ideológica presumida.

De acordo com os dados informados no Portal da Transparência e pareceres fornecidos pelo Controle de Interno, observa-se que o município adotou a dispensa de licitação em grande escala em 2020, comparado com 2019 conforme apresentado no gráfico 1 abaixo.

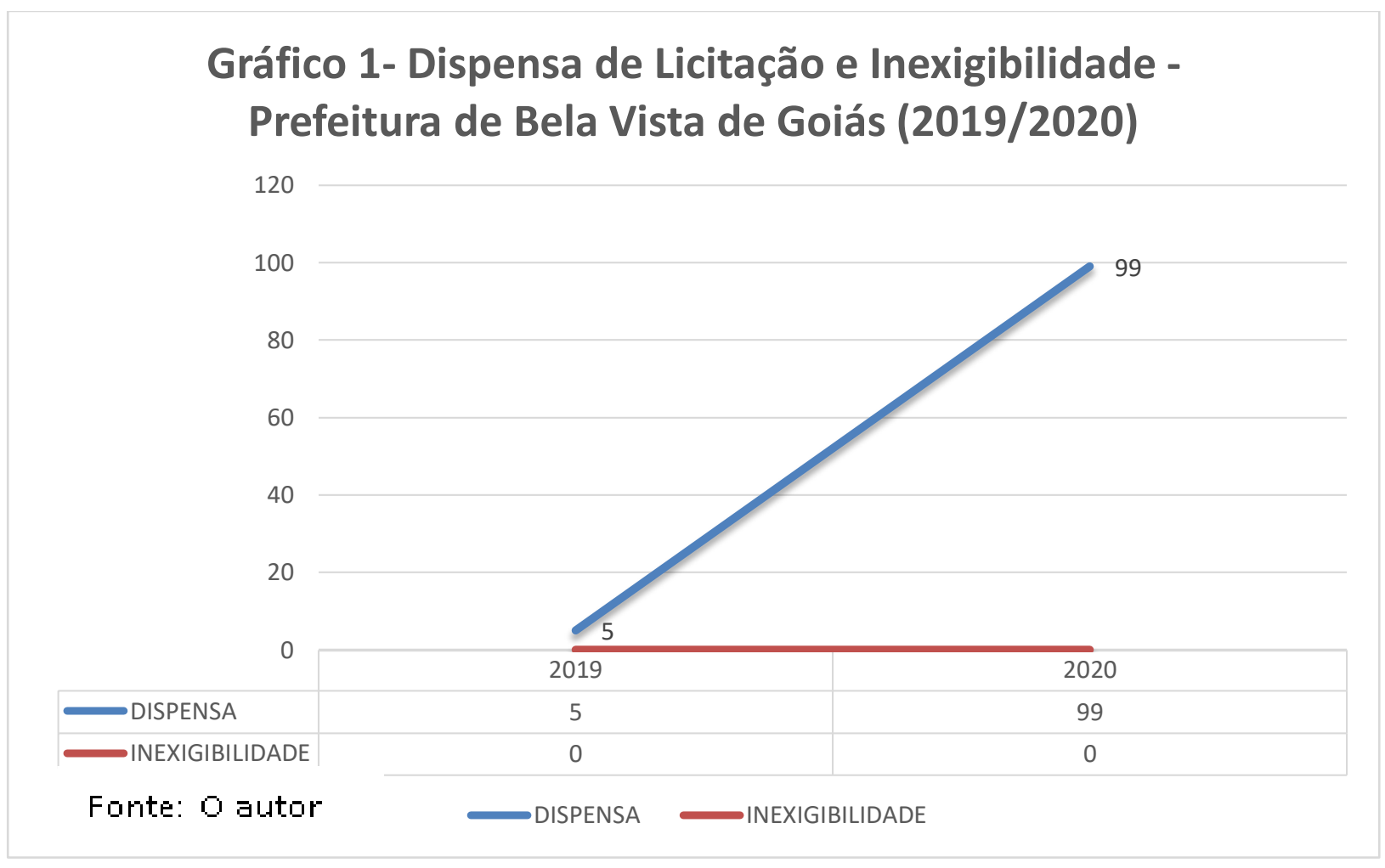

Nota-se que este aumento no número de dispensa se deu devido previsão legal da Lei Federal ${ }^{\circ}$ 13.979/2020, a qual dispõe sobre as medidas para enfrentamento da emergência de saúde pública de importância internacional decorrente do coronavírus, responsável pelo surto de $2020 \mathrm{em}$ seu artigo $4^{\circ}$ "fica dispensada a licitação para aquisição de bens, serviços e insumos de saúde destinados ao enfrentamento da emergência de saúde pública de importância internacional decorrente do Coronavírus de que trata esta Lei”. (BRASIL, 2020), pois bem, A Lei Federal proporcionou a dispensa de licitação em todas as esferas, tanto Federal, Estadual e Municipal, com isso, foi permitido aquisição de bens, serviços e insumos de saúde sem o devido processo de licitação, vale destacar que nesse caso, a Lei Federal não fixou valor máximo de compra, liberando o uso da dispensa de licitação desde que fosse para produtos ou insumos destinados ao enfrentamento da pandemia, porém na maioria das vezes realizada de forma irregular.

Impactando negativamente as contas públicas da União, Estados e Municípios, levando em consideração a alta adesão da dispensa em um curto período de tempo, sem que pudesse realizar pesquisas de preços numerosas, praticando preços acima de mercado, consequentemente deixando de 
utilizar a proposta mais vantajosa economicamente ou então deixando de obedecer aos preços já acordados ou fixados por alguma tabela de parâmetro de preço médio.

Resta esclarecer, que, a Lei Federal n ${ }^{\circ}$ 13.979/2020 aplica-se a todos os órgãos e as entidades que integram a União, os estados, o Distrito Federal e os municípios, inclusive suas empresas estatais, dado que, na forma do disposto no art. 24, inc. XXVII, da Constituição Federal: "A União tem competência privativa para legislar normas gerais sobre licitações e contratações públicas" (BRASIL, 1988). ainda assim, muitos Estados e Municípios publicaram Decretos ratificando as disposições da Lei Federal e o uso da dispensa de licitação, sempre respeitando a exigência do objeto da dispensa, sendo permitido nesse caso apenas produtos ou insumos destinados ao enfrentamento da pandemia.

Nesse mesmo sentido o Tribunal de Contas da União, no seu dever de fiscalizador, preferiu uma sentença que deixou claro a interpretação da Lei Federal n 13.979/2020:

Tribunal de Contas da União (2020):

\begin{abstract}
"Os processos de contratação relacionados ao enfrentamento da crise do novo coronavírus (covid-19) devem ser instruídos com a devida motivação dos atos, por meio, no mínimo, de justificativas específicas acerca da necessidade da contratação e da quantidade dos bens ou serviços a serem contratados, com as respectivas memórias de cálculo e com a destinação a ser dada ao objeto contratado (art. $4^{\circ}$-E, § $1^{\circ}$, da Lei 13.979/2020)" (Tribunal de Contas da União, Acórdão 1335/2020 Plenário).
\end{abstract}

Tendo em vista os Decretos Estadual e Municipal, ${ }^{\circ}$ 9.633/2020 e ${ }^{\circ} 104 / 2020$, que ratificaram as disposições da Lei Federal n ${ }^{\circ} 13.979 / 2020$, decretando situação de calamidade pública no estado de Goiás e no município pesquisado, e permitindo a dispensa de licitação para o enfretamento do coronavírus, verifica-se obviamente que a secretaria que mais utilizou da dispensa de licitação foi a Secretaria de Saúde, em especial o Fundo Municipal da Saúde de Bela Vista De Goiás, concentrando a maior parte das dispensas para aquisição de insumos para o enfrentamento do coronavírus. Neste caso, é possível comprar diretamente, por exemplo, máscaras, luvas, sapatilhas, álcool 70\%, touca, avental, cama hospitalar, ventilador pulmonar, monitor multiparamétrico, ambulâncias, etc. Além disso, podem-se contratar serviços como manutenção preventiva e corretiva de ventilador pulmonar, leitos de UTI, mão de obra terceirizada para separação e transporte de medicamentos, conforme apresentado no gráfico 2 abaixo.

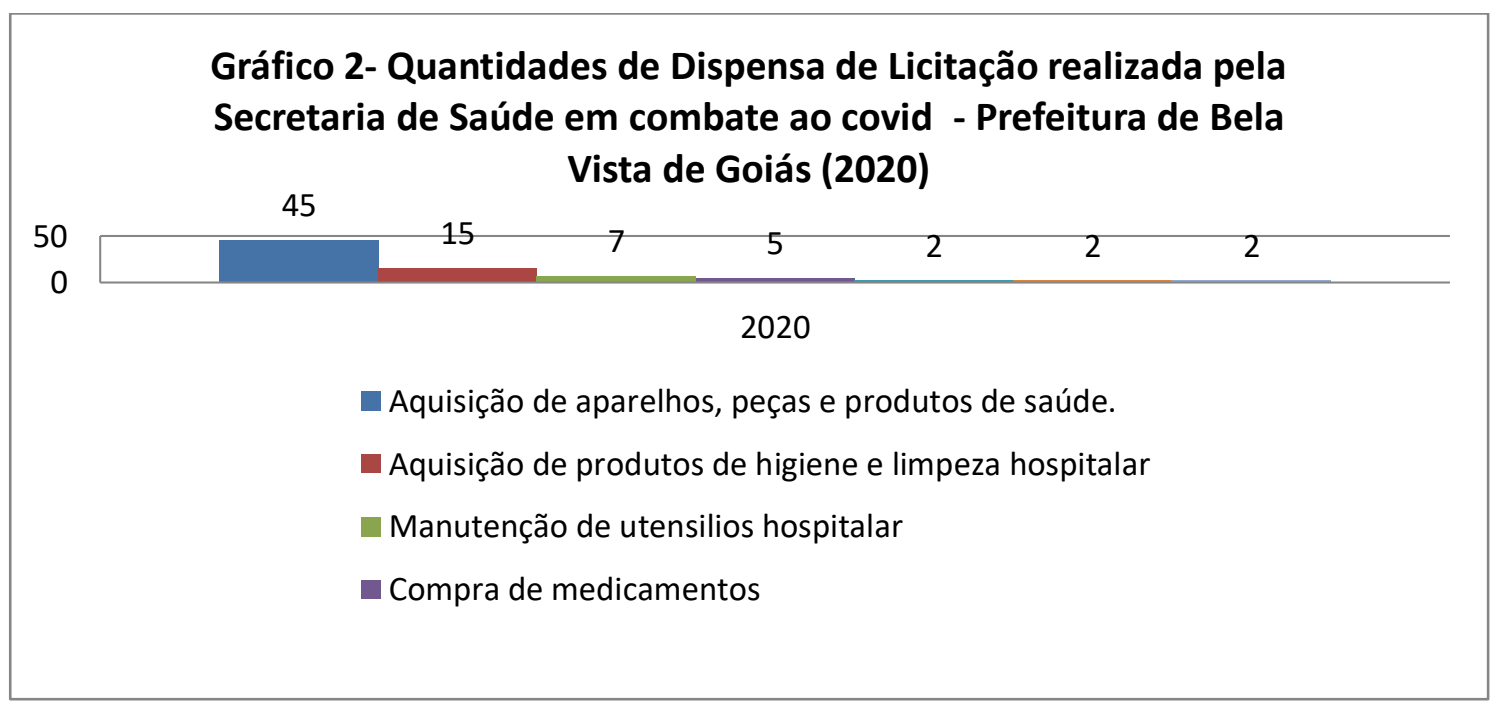


Com a finalidade de fomentar ainda mais a utilização da dispensa em meio a pandemia, por conta da celeridade na compra e urgência, o Governo Federal publicou a Medida Provisória $n^{\circ} 961$ de 06/05/2020 que "estabelece novos limites da dispensa de licitação, que agora chegam até R\$ 100 mil para obras e serviços de engenharia ou da mesma natureza que possam ser realizados no mesmo local e em conjunto, e até R \$ 50 mil para outros serviços, compras e também alienações" (BRASIL, 2020). Essa Medida Provisória contribuiu grandiosamente para o elevado número de dispensas realizadas pelo município em 2020, resta informar que sua vigência está condicionada apenas durante o estado de calamidade pública, reconhecido pelo Decreto Legislativo nº 6, de 20 de março de 2020.

Constata-se que em toda dispensa de licitação realizada pelo município de Bela Vista de Goiás houve o processo de contratação decorrente da Lei $n^{\circ} 13.979 / 2020$, existindo nexo de causalidade entre a aquisição do bem ou serviço e o combate à situação emergencial, não se admitindo contratação com finalidade diversa. Ressalta-se que foi analisado caso a caso evitando pareceres com dados previamente classificados que contenham características similares.

É interessante notar que em 2019 e 2020 a maior parte das dispensas de licitações realizada pelo município foi dotada seguindo o art. 24, mais especificamente os incisos I, II e V da lei 8.666/1993.

I - para obras e serviços de engenharia de valor até $10 \%$ (dez por cento) do limite previsto na alínea "a", do inciso I do artigo anterior, desde que não se refiram a parcelas de uma mesma obra ou serviço ou ainda para obras e serviços da mesma natureza e no mesmo local que possam ser realizadas conjunta e concomitantemente; II - para outros serviço: Fonte. O autor até $10 \%$ (dez por cento) do limite previsto na alínea "a", do Fonte: O autor o anterior e para alienações, nos casos previstos nesta Lei, desde que não se refiram a parcelas de um mesmo serviço, compra ou alienação de maior vulto que possa ser realizada de uma só vez. [...] V - quando não acudirem interessados à licitação anterior e esta, justificadamente, não puder ser repetida sem prejuízo para a Administração, mantidas, neste caso, todas as condições preestabelecidas. (Brasil, 1993)

Verifica-se que estas justificativas foram as mais utilizadas pela Administração Pública em 2019 e 2020, uma vez que os incisos I e II permite a dispensa quando tratar-se de contratação de obras e serviços de engenharia ou para compras e serviços de valores baixos, que inviabiliza o devido processo licitatório (BRASIL, 1993). Uma vez que, os insumos de combate ao coronavírus e outros produtos hospitalares, se enquadram dentro desses valores limites, por não ser tão altos.

Neste caso, resta atentar para que a Administração planeje as aquisições e/ou contratações a fim de evitar o fracionamento da despesa, o qual é caracterizado por aquisições frequentes dos mesmos produtos ou realização constante de serviços da mesma natureza, podendo ultrapassar o valor, se somados os valores fracionados, sendo essa conduta ilegal conforme estabelece o Manual De Compras Diretas do Tribunal de Contas da União. Sendo assim, ao apreciar os processos de dispensa de licitação realizados pelo município em estudo constata-se que não constam irregularidades.

Já o inciso V do artigo 24 da Lei Federal nº. 8.666/1993 permite a dispensa quando a licitação for declarada deserta ou fracassada, ou seja, houve a tentativa por duas vezes de realizar a contratação por meio de procedimento licitatório, na modalidade Pregão Presencial, porém não houve nenhuma empresa interessada (BRASIL, 1993). Neste sentido, não houve aprofundamento de estudo de licitação deserta e fracassada, por ser identificado uma quantidade mínima de processos e pareceres, no caso de licitação fracassada depreende-se que a omissão ou demora na realização de processos de aquisição dos produtos poderia causar prejuízo à Administração, o que justifica assim a contratação 
por dispensa pautada no inciso do artigo supracitado, situação ocorrida em 2019, após o município aqui em estudo, na tentativa por duas vezes de realizar a contratação por meio de procedimento licitatório, contratou uma empresa para fornecimento de água mineral, em atendimento às necessidades da Secretaria Municipal de Administração e Governo desta municipalidade com fundamentação no referido artigo.

Ademais, não foi possível identificar nenhum processo que se utilizou da inexigibilidade de licitação no Município de Bela Vista de Goiás nos anos de 2019 e 2020, conforme previsto no artigo 25 da Lei Federal no 8.666/1993:

É inexigível a licitação em quando houver inviabilidade de competição, especial: I para aquisição de materiais, equipamentos, ou gêneros que só possam ser fornecidos por produtor, empresa ou representante comercial exclusivo, vedada a preferência de marca, devendo a comprovação de exclusividade ser feita através de atestado fornecido pelo órgão de registro do comércio do local em que se realizaria a licitação ou a obra ou o serviço, pelo Sindicato, Federação ou Confederação Patronal, ou, ainda, pelas entidades equivalentes; II - para a contratação de serviços técnicos enumerados no art. 13 desta Lei, de natureza singular, com profissionais ou empresas de notória especialização, vedada a inexigibilidade para serviços de publicidade e divulgação; III - para contratação de profissional de qualquer setor artístico, diretamente ou através de empresário exclusivo, desde que consagrado pela crítica especializada ou pela opinião pública. (BRASIL, 1993)

Talvez por ser uma situação muito restrita e remota, pois essa inviabilidade pode ser tanto pela exclusividade do objeto a ser contratado, como pela falta de empresas concorrentes. O mais comum é quando existe apenas um fornecedor para determinada demanda, o que normalmente não acontece devido o mercado estar cada vez mais competitivo e abrangente.

\section{Considerações Finais}

A pesquisa forneceu resposta à problemática proposta, vez que verificou que a Administração Pública do município de Bela Vista de Goiás utilizou de forma correta a dispensa de licitação, porém com algumas ressalvas. Constatou-se que as dispensas de licitação realizadas nos anos de 2019 e 2020 atenderam os requisitos legais dos dispositivos que autorizam a contratação direta, porém deixaram de atender alguns procedimentos formais: elaboração de pareceres pela Secretaria de Controle Interno e divulgação no Portal da Transparência, situação essa, que foi identificada ao fazer a busca das informações no referido site.

O município ao deixar de disponibilizar estas informações deixa de cumprir com o princípio da publicidade, no qual impõe que "os atos e termos da licitação no que se inclui a motivação das decisões sejam efetivamente expostos ao conhecimento de quaisquer interessados" (BRASIL, 1993). É um dever de transparência, em prol não apenas dos disputantes, mas de qualquer cidadão, conforme prevê o artigo 37 da Constituição Federal, "A Administração Pública direta e indireta de qualquer dos Poderes da União, dos Estados, do Distrito Federal e dos Municípios obedecerá aos princípios de legalidade, impessoalidade, moralidade, publicidade e eficiência". (BRASIL, 1988), conforme salienta 
alguns autores "A Lei de Acesso à Informação tem por objetivo jogar luz à obscuridade quanto aos atos praticados pela Administração Pública. (Mello, e cols, 2016: 363)

Talvez o problema esteja relacionado aos portais de transparências terceirizados, salienta, Dias, e cols:

Portais de transparência, implantados por terceirização, tendem a ser mais frágeis e encontrar mais dificuldade em manter os níveis de transparência ativa dependendo da integração dos sistemas e do fluxo de informação contábil-orçamentária implantado localmente, e o nível de transparência é uma decisão política, dada a possibilidade de parametrização dos portais (Lidiane Nazaré da Silva Dias, André Carlos Busanelli de Aquino, Polyana Batista da Silva, Francivaldo dos Santos Albuquerque, 2020:12).

Verificou-se também, que, nem todas as dispensas de licitação realizadas pelo município possuía pareceres elaborados e autorizados pela Secretaria de Controle Interno, deixando de cumprir o princípio da motivação, no qual determina que a autoridade administrativa deva apresentar as razões que a levaram a tomar uma decisão, no qual deverá ser fundamentada com as normas legais que autorizaram a dispensa de licitação.

Em relação à dispensa decorrente da pandemia, cumpre frisar que, o objeto da dispensa deve limitar-se a aquisição de bens e serviços indispensáveis ao atendimento da situação de emergência e saúde pública, a fim de evitar utilizar da dispensa de licitação para compras de bens e produtos não contemplados na Lei Federal $\mathrm{n}^{\circ}$ 13.979/2020. Neste sentido, vale destacar que não foi possível analisar se ocorreu tal situação, talvez por ter ocorrido uma grande quantidade de dispensa em um curto período, não foram localizados todos os pareceres com os dispositivos jurídicos e fundamentos da dispensa decorrente da pandemia do COVID-19, que deveriam ser disponibilizados pelo Controle Interno da prefeitura ou serem divulgados no Portal da Transparência do município.

Sabe-se que há fragilidades e lacunas na atual lei de licitação, o que favorece a ocorrência de fraudes nas licitações, que levam a danos e prejuízos nos casos de dispensa e inexigibilidade de licitação de forma inadequada. A Lei Federal $n^{\circ}$ 8.666/1993 prevê penalidades mais severa aos licitantes, sendo brando em relação às penalidades ao gestor público, conforme entendimento do Superior Tribunal de Justiça "o crime previsto no art. 89 da Lei de Licitações e Contratos Administrativos, exige, para sua caracterização a presença de especial finalidade de agir na conduta do agente, consistente na intenção deliberada de causar lesão ao erário. Exige-se, ainda, que a lesão se efetive, ou seja, que exista prejuízo ao ente público. Tais condições constituem elementares do tipo penal, devendo estar presentes para fins de tipicidade da conduta".

Pode-se dizer que uma grande lacuna na atual lei de licitação é a participação e fiscalização tímida do órgão fiscalizador, nesse caso, o Tribunal de Contas dos Municípios do Estado de Goiás, a fiscalização dos processos é realizada por amostra e sorteio, deixando de analisar muitos processos que poderiam ser constatado alguma irregularidade. Para tanto, o órgão fiscalizador deveria implantar um programa de monitoramento e acompanhamento dos procedimentos licitatórios, em tempo real, para que a população pudesse fiscalizar os processos de forma mais simplificada.

Por fim, para evitar possíveis violações da norma é de suma importância que o gestor público observe os ritos dos dispositivos da Lei Federal $n^{\circ}$ 8.666/1993 e pratique todos os atos de forma objetiva e justificada, utilizando sempre as ferramentas para subsidiar qual a melhor forma de proceder em determinadas situações, e assim legitimar a contratação direta sem indícios de contratações desarrazoadas e incompatíveis com o interesse público perseguido. 


\section{Referências Bibliográficas}

Oliveira, Anderson de. (2009). Licitação: fraudes comuns nas aquisições de bens, enquadramento legal e procedimentos preventivos. Trabalho de Conclusão de Curso. Universidade Federal de Santa Catarina, Florianópolis, Brasil. Acessado em 12 de Março de 2020, de: https://repositorio.ufsc.br/handle/123456789/126828

Bittencourt, Sidney. (2014). Licitação passo a passo. Belo Horizonte: Fórum.

Brasil. (1993, 21 de junho de). Lei $n^{o}$ 8.666. Diário Oficial da União, 22 jun. 1993. Dispõe sobre normas para licitações e contratos da Administração Pública e dá outras providências Constituição Federal, 1988. Acessado em 12 de Março de 2020, de: http://www.planalto.gov.br

Brasil. (2020, 20 de março de). Medida Provisória $N^{o}$ 926. Dispõe sobre procedimentos para aquisição de bens, serviços e insumos destinados ao enfrentamento da emergência de saúde pública de importância internacional decorrente do coronavírus. Acessado em 22 de Março de 2020, de: http://www.planalto.gov.br

Brasil. (2020, 06 de fevereiro de). Lei $N^{o} 13.979$ Dispõe sobre as medidas para enfrentamento da emergência de saúde pública de importância internacional decorrente do coronavírus responsável pelo surto de 2019. Acessado em 22 de Março de 2020, de: http://www.planalto.gov.br

Brasil. (2020). Portal da Transparência do Município de Bela Vista de Goiás. Acessado em 22 de Março de 2020, de: https://belavistadegoias.megasofttransparencia.com.br/. Acesso em 01/11/2020.

Brasil. Tribunal de Contas da União, 2020. Disponível em https://portal.tcu.gov.br/.

Brasil. Superior Tribunal de Justiça, 2020. Disponível em https://www.stj.jus.br/sites/portalp/Paginas/Comunicacao/Noticias/Crime-de-dispensa-ilegal-delicitacao-exige-prova-de-dolo-e-de-dano-ao-erario.aspx.

D’Avila, Vera Lúcia Machado. (2005). Dispensa e inexigibilidade. São Paulo: Malheiros.

Di Pietro, Maria Sylvia Zanella. (2004). Direito Administrativo. São Paulo: Atlas.

Mello, Elizabete Rosa de., Policiano., Eliane Beatriz Cunha., \& Andrade, Marcella Coelho. (2016). A (i)legalidade da regulamentação da licitação por adesão e a aplicação da lei de acesso à informação. Revista de Administração Pública, 3(2), 343-366. Acessado em 07 de Abril de 2020, de https://doi.org/10.11606/issn.2319-0558.v3i2p343-366

Fernandes, Jorge Ulisses Jacoby. (2016). Contratação Direta Sem Licitação. Lisboa: Fórum.

Justen Filho, Marçal. (2008). Curso de Direito Administrativo. São Paulo, Saraiva, 2008.

Dias, Lidiane Nazaré da Silva., Aquino., André Carlos Busanelli de., Silva, Polyana Batista da., \& Albuquerque, Francivaldo dos Santos. (2020). Terceirização de portais de transparência fiscal em prefeituras municipais. Revista de Administração Pública, 14(1), 1-15. Acessado em 07 de Abril de 2020, de: https://doi.org/10.11606/issn.1982-6486.rco.2020.164383

Meirelles. Hely Lopes. (2004). Direito Administrativo Brasileiro: $29^{a}$ Edição, São Paulo, Malheiros Editores. 